\title{
Visit to India
}

\section{EDITORIAL}

A. The All India Leprosy' Conference, December 1959, Bombay

The 7th Conference of the All India Leprosy Workers and the 4th of the Indian Association of Leprologists was a joint affair, held in Bombay, 14th-18th December 1959. This highly successful Conference had as Chief Patron Shri Sri Prakasa, Governor of Bombay, and as Patrons Shri Y. B. Chavan, Chief Minister, and Dr. Jivraj N. Mehta, Minister of Finance, and as Chairman of the Executive Committee Shri N. K. Tirpude, Minister for Social Welfare. The Secretary was Dr. T. B. Patel, and Joint Honorary Secretaries Dr. P. Kapoor and Dr. J. N. Vazifdar. Two publications for the Conference were issued by Hind Kusht Nivaran Sangh (Indian Leprosy Relief Association). These were the "Programme", which contained summaries of the 29 papers delivered at the Conference, and "Souvenir" which contained 100 pages and 76 illustrations, chiefly made up of the following articles:-

All India Leprosy Workers' Conferences

T. N. JAGADISAN

Indian Association of Leprologists, Its Origin and Development

K. R. Chatterjee

Government of India and Leprosy Control

Y. K. Subrahmanyam

Leprosy Control Work in Bombay State

T. B. PATEl and

P. KAPOOR

Pathology of Early Lesions in Leprosy

The Diagnosis of Leprosy and its Difficulties

V. R. KHANOLKAR

The Leprosy Patient and his Treatment

\section{S. N. Chatterjee}

E. MUIR

The Present Concept of the Role of Isolation in the Control of Leprosy Diet for Leprosy Patients

\author{
N. Figueredo \\ M. V. RADHAKRISHNA \\ RAO and M. S. \\ KoTNIS \\ Paul W. Brand \\ M. D. AMTE \\ M. Diwan \\ P. SEN
}

The Role of Physiotherapy in Leprosy

Rehabilitation of Leprosy Patients

Difficulties in the Rehabilitation of Leprosy Patients

Leprosy and Law

Bibliography of Publications on Leprosy from India

N. MuKerJeE

The Editor was present throughout at the actual Conferences and enjoyed them and the discussions very much. The best way to give readers an idea of the interesting fare offered would be to give our own summaries of the papers delivered. 
1. Dr. S. N. Chatterjie dealt very fully and helpfully with The Diagnosis of Leprosy and its Difficulties. His paper in full text, with 62 illustrations, is available in the Souvenir, p. 38 . He began with skin conditions simulating leprosy, from leucoderma to occupational dermatitis, and dealt with dermal leishmaniasis, neurofibroma, many nerve conditions both primary and secondary, vascular conditions, and gave wise advice about the assessment of thickened nerves, and bacilli in smears, and a warning that leprosy is sometimes missed owing to some complication, e.g. a change in a leprotic lesion which causes it to be mistaken for erysipelas or cellulitis. From experience in Africa, about the only thing we might add to Dr. Chatterjee's big list is onchocerciasis.

2. Dr. Dharmendra read a paper on the Classification of Leprosy. He described the position reached at the Tokyo Congress, 1958. The maculo-anaesthetic group favoured by Indian leprologists does not seem acceptable to the Hispano-American and LusoAmerican workers, and the Tokyo Congress made no recommendation on this point. Indian leprologists want polyneuritic lesions to be placed in a separate group, in the sense of periphero-neuritic. Dr. Dharmendra comments that though it has been agreed that the basis of primary classification of leprosy should be clinical, the stress always tends to be placed on histopathology.

3. Dr. N. Figueredo also read a paper on the Classification of Leprosy. From his studies using Dharmendra antigen and bacteriological examinations on patients and contacts he recognises leprosy in the following stages: infected or silent phase, primary lesions, pre-nonlepromatous macules, minor or major tuberculoid, maculoanaesthetic, indeterminate, reactional tuberculoid, borderline, primary or pure polyneuritic, prelepromatous macules, and lepromatous. The progress of all lesions tends either towards the polyneuritic or the lepromatous. The indeterminate also tends this way or to the lepromatous through the reactional tuberculoid and borderline phases. Transition from the maculo-anaesthetic to the minor or major tuberculoid has not been observed, nor the reverse. Minor and major tuberculoid and the maculo-anaesthetic tend only towards the polyneuritic. He recommends the inclusion of reactional tuberculoid in the intermediate group, and applying "borderline" to lesions on the verge of progression to lepromatous.

4. DR. J. Ross INNES of London read a paper on Mercaptan Compounds in Leprosy and Tuberculosis. G. W. DrIVER and G. E. DAviEs contributed to this paper a valuable survey of the literature on the mercaptan compounds. The clinical study of these hopeful compounds began in 1950 by Del Pianto who tried sodium ethyl sulphate against animal and human tuberculosis and in 1958 reported at the 7th International Congress of Leprology that he had had good results against leprosy. Other workers studied ethyl mercaptans, and 
in 1956 Davies and Driver and others of ICI Research Laboratories reported on the study of 200 mercaptan and related compounds in mice tuberculosis and selected diethyl dithiolisophthalate as the most active. They also found it to be effective by inunction. Davey and others have ruported on its action in human leprosy and the results so far suggest an unusually rapid bacteriocidal effect. Drug resistance develops at about the fourth or fifth month when the ICI product Etisul is used alone, but Davey has latterly found that the use of DDS and DPT by mouth from the beginning of the trial delays indefinitely the onset of drug resistance and the total effect is a reduction in the bacterial index greater and faster than anything known before. There is a strong case for wider clinical trials against leprosy of this very interesting drug. At the present time, trials are in progress against human tuberculosis with equally hopeful results. It is not likely that it will be an expensive drug when finally it arrives on the market.

5. Drs. N. MukerJee and P. Ghosal described Recent Developments in the Chemotherapy of Leprosy, discussing depot injections of DDS, newer sulphone derivatives, new drugs and antibiotics and they called for more trials on many of them, both alone or in combination, for any therapy which is more effective than DDS will be welcome. For parenteral action they consider the best is a depot suspension of microcrystalline DDS in $0.2 \%$ sodium carboxy methyl cellulose in normal saline. They found DDSO as effective as DDS. DPT is as effective as DDS and a useful alternative drug under certain circumstances. Further trial with Etisul is necessary, also the benzaldehyde derivative of INH. Combination of DDS with either INH, DPT, or Etisul, seems to produce a little better effect than DDS alone.

6. DR. A. T. RoY read a paper on the Treatment of Leprosy with SU $1906(D P T)$. He tried SU 1906 or 4-butoxy-4 dimethyl-aminodiphenylthiourea in 5 lepromatous, 1 major tuberculoid, which was bacterially positive, and 1 minor tuberculoid (this was a child aet. 4 years). The children in the series were given dosage of 0.5 to $1.5 \mathrm{~g}$. daily. The adults were given 1 to $3 \mathrm{~g}$. These doses were well tolerated and clinical improvement was noted. The adult doses were then tried on the children and were well tolerated. The lepromatous cases had their dosage gradually increased, and all took $4.5 \mathrm{~g}$. without any toxic signs or reaction. One of the lepromatous cases began to show signs of reaction when $5 \mathrm{~g}$. dose was given, but none of the 7 cases showed any sign of reaction with the recommended dose of 1 to $3 \mathrm{~g}$. A progressive reacting case was now included in the series, who was intolerant to sulphone of any type. He has done well on $2.5 \mathrm{~g}$. without reaction, and with rapid clinical improvement.

The bacillary index was influenced, with results much the same as Davey found in his cases, though with ups and downs.

7. Drs. J. E. Somerset, N. Mukerjee and N. R. Sen dealt with 
Lagophthalmos in Leprosy: Its Surgical Treatment. Complete or incomplete defect of closure of the eyelids is common in leprosy, often accompanied by ectropion of the lower lid. This leads to exposure keratitis and its complications. The more common operation available is lateral tarsorrhaphy, but Axenfeld's operation is preferable in some cases. This consists of the insertion of a silk suture under the skin of the upper and lower lids and under the lateral and medial tarsal ligaments. The size of the palpebral fissure can thus be adjusted to its optimum by tightening the suture. The stitch is left in position for-several months until its track has become fibrous. The removal of the stitch thus leaves a fibrous band which takes over its action. The authors used this operation in 6 cases with good success.

8. Dr. N. H. ANTIA described the Correction of Facial Deformity' in Leprosy by Plastic Surgery. Though large numbers of leprosy cases are now being cured, if the treatment has been started late there will be many left with disfigurements and deformities. Deformities of the hand and limbs will need surgical correction in order to help the patient to become a useful citizen, and disfigurements of the face by perpetuating the stigma attached to leprosy will hinder rehabilitation. The author therefore has taken special interest in the correction of facial deformities in the Kondhwa Leprosy Hospital. (a) The sunken nose is the most striking of these and he has found the operation of postnasal epithelial inlay, by supplying fresh lining through an intraoral operation, to be very satisfactory, even in advanced cases, and support can then be provided by a dental prosthesis or a bone graft. (b) Total destruction of the nose is best dealt with by a tube pedicle rhinoplasty. (c) Lagophthalmos or paralysis of the orbicularis muscle of the eye, which is common in leprosy and may lead to loss of sight, can be corrected by taking advantage of the fact that the adjacent temporalis muscle innervated by the 5 th nerve is usually not affected. A fascial sling is made to encircle the palpebral fissure and attached to an innervated slip of the temporalis muscle. Its contraction closes the eye and corrects the deformity. This method is better than lateral tarsorrhaphy, which is apt to fail in part by recurrence of the trouble in the residual unclosed portion of the palpebral fissure. $(d)$ Lost eyebrows can be replaced by grafting hairbearing scalp as a free graft, or as a temporal artery pedicle flap. (e) A face lift can be given to correct the wrinkled appearance of premature ageing. $(f)$ Elongated ear lobes can be trimmed, and thickened skin and nodules shaved down. $(g)$ Perforation of the palate can be closed using a plastic procedure which sufficiently elongates the soft palate to produce normal speech. The author makes a plea for the opening of centres for plastic and reconstructive surgery and for training surgeons in this highly satisfactory field.

9. Dr. R. H. Thangaraj dealt with Foot Ulceration in Leprosy. 
He wished to stress the distinction between the pathological and mechanical factors in the causation of ulcers of the feet and absorption of bones. Arterial changes may both lead to ulceration and result from it. The limitation of blood supply to an ulcer in leprosy is not due to vasoconstriction but to vasostrangulation by a mass of nonelastic fibrous tissue caused by previous ulceration. The first ulcer is due to an excessive amount of walking, a badly fitting shoe, or some slight injury. It can be healed, but as it heals creates fibrous tissue which in its turn predisposes to further ulceration. At the time of the first ulcer the patient will be much helped by hospitalization and education in the prevention and care of ulcers. The author lists causative mechanical factors; $(a)$ excessive walking; $(b)$ injuries from sharp stones, thorns, and nails in the shoes; (c) irregular weight bearing; $(d)$ the concentration of weight at certain points of the foot ; (e) the projection of bone downwards towards the sole of the foot causing localised pressure; $(f)$ drop foot and inversion caused by paralysis. For the last mentioned the standard operation is to fix the tibialis posterior to the middle cuneiform bone with stainless steel wire. The author's modification is to pass the tibialis posterior through the interosseous space about 5 inches $(12.7 \mathrm{~cm}$.) above the ankle and then through the extensor digitorum longus and then into the tibialis anterior. A plaster below the knee is applied to maintain the foot in dorsiflexion, and the plaster is removed in 4 weeks. Physiotherapy is fully used.

10. Dr. D. N. Bose dealt with Plaster Therapy with Physiotherapy in Deformities and Chronic Neurological Syndromes in Leprosy. Patients. He described simpler methods which can be used with success in default of skilled surgical personnel and equipment. The application of plaster rests and heals many deformities, and for the prevention of recurrence he gives physical exercises to the parts, regular massaging with oil, preferably hydnocarpus oil, and subcutaneous injections of Hydnocreol in doses of 3 to $4 \mathrm{ml}$. at least twice a month in the deformed parts and by the sides of the nerves.

11. Dr. M. Nishiura gave a paper on Electron Microscopic Studies of Human Leprosy Lesions. He has used metal-shadowing of ultra-thin sections of leprosy lesions to study the fibrous elements by electronmicroscopy (collagen, reticulin, and elastic fibres). In tuberculoid lesions many collagen fibrils are separated from each other or dissolved, but elastic fibres look normal and are easily recognised. In lepromatous lesions, collagen, reticulin, and elastic fibres are well preserved, though the elastic fibres are a little difficult to identify. The necrotic process in tuberculoid skin and nerve lesions was also studied. Intracytoplasmic coagulative necrosis was noted in tuberculoid skin lesions in a few isolated cells, but in nerve lesions it was found on a large scale, and the whole nerve trunk may be packed with necrotic masses. 
12. Drs. M. Nishiura, S. M. Sirsat, and V. R. Khanolgar also reported on Electronmicroscopic Study of Lepros'y Lesions. After metal-shadowing of ultra-thin sections from the skin and great auricular nerves the electronmicroscopic study showed that the collagen fibrils are not damaged in lepromatous lesions, but in tuberculoid they are often separated from each other or entircly absent. Elastic fibres are more easily found in tuberculoid than in lepromatous lesions, and they do not appear abnormal. A few isolated necrotic cells which show coagulative changes in the cytoplasm are found in tuberculoid skin lesions. The necrotic process in tuberculoid nerve lesions begins as a coagulation of the cytoplasm and the formation of myeloid bodies and droplets of lipid inside the cytoplasm of epithelioid cells. Destruction of the cell membrane of these necrotic epithelioid cells is followed by the release of various degenerated cell materials which form a caseation necrosis of the whole nerve trunk. The commonest form of the necrotic mass is a helicoidal thread at least 15 to $25 \mu$ in breadth. These threads mass together and may be found in an occasional necrotic cell of the skin and more widely in necrotic lesions of the peripheral nerves.

13. DR. V. R. Khanolkar has a paper on the Pathology of Early Lesions in Leprosy, which was published in the Souvenir of the Conference pp. 30-37 and is abstracted here and given for the sake of completeness. The paper has one schematic text-figure of the cellular elements inside the endoneurium and perineurium in relation to the descending nerve fibre in leprosy. There are also 13 illustrations of the histology of nerve fibres and cellular elements in leprosy, some of them electronmicrographs. About 12 years ago Dr. Khanolkar began a careful clinical and immunological examination and study of the histology of the skin, in early cases of leprosy and contacts. He later added a standardised lepromin test, and fluorescence microscopy for the fluid obtained from skin biopsies, newer techniques for studying the condition and structure of the peripheral nerve fibres, and finally electronmicroscopy for the finer structure of cell constituents and the intercellular material.

The group of contacts with leprosy comprised 138 adults and 24 children who were clinically free of leprosy. Of them the 24 children and 68 adults showed the presence of acid-fast bacilli in the skin, after application of a concentration technique to the skin biopsies. Later more adults became bacillus-positive and a high proportion of those who were lepromin-negative became leprominpositive. Of the total group of 162 persons, 69 developed recognisable physical signs of early leprosy.

Contacts of tuberculoid and lepromatous leprosy were next studied separately. Clinically and bacterially positive leprosy developed in $27 \%$ of those in contact with the tuberculoid type and $39 \%$ in those in contact with the lepromatous. An arbitrary division 
of leprosy patients into "open" and "closed" types therefore seems unjustifiable.

It is not possible to predict which of those contacts who show leprosy bacilli in their skin will develop leprosy and which will escape it, so this can be called the "silent phase". In the histology of this early stage there is nothing special, except for the occasional finding of a histiocyte with one or two intact or fragmented acid-fast bacilli in the cytoplasm. Sometimes the histiocytic cytoplasm takes a granular or diffuse basic stain which does not decolourise with weak acids. Khanolkar has found this only in the early stages of leprosy and calls such cells "fuchsinophil cells". In the next phase there is a non-specific type of cellular response; this is the indeterminate phase. Later the cell response becomes typical of lepromatous, dimorphous, or tuberculoid leprosy.

In the histology of all these three types the bacilli seem to prefer to be found in the axoplasm of the cutaneous nerves and there is an inflammatory response which tends to be located in areas of the dermis which are richly supplied with nerve filaments, such as hair follicles, sweat and sebaceous glands, and erector pili muscles. The sensory cutaneous and the sympathetic fibres seem to be affected early and greatly, and show the most of later damage in all forms of the disease.

In lepromatous leprosy the bacilli gain access to the axoplasm of the preterminal axons of regenerating fibres. The electronmicroscope shows bacilli lying interspersed with mitochondria. The bacilli seem to move towards the dorsal root ganglia and go no further. The axoplasm shows degenerative changes and looks worm-eaten in ultra-thin sections, and bacilli with a lipoid covering are seen lying in the section. The myelin sheath also undergoes progressive degeneration. At intervals along the nerve fibre there are clumps of great multiplication of bacilli, which probably burst out in the endoneural and perineural spaces. Contemporaneous with the degenerative changes regenerating nerve fibres migrate along the collapsed Schwann tubes from the adjacent unaffected nerve fibres, and the Schwann cells convert into ribbonlike bands called "Büngner's Cords". The bacilli seem to be able to remain a long time in the Schwann cell cytoplasm unharmed. The bacilli which escape out of the nerve fibres are taken up by the endoneural cells and histiocytes, which pack closely into a sheath of lepra cells round the nerve fibres. The pressure of packed lepra cells and resulting ischaemia seems to be the main cause of disturbance in structure and function of the nerves.

In the dermis the early change in lepromatous leprosy is the appearance of collections of chronic inflammatory cells in strands or groups around nerve twigs and plexuses. The grouped cells form a richly vascular granulation tissue on a reticulum of very fine fibres. 
Most of the cells are histiocytes. In their cytoplasm the bacteria multiply and quickly come to be surrounded by a lipoid envelope which under the electron microscope appears as an opaque droplet. In this droplet clear zones appear which adjoin the bacteria. These clear zones fuse with the adjoining coverings of multiplying bacteria, and finally the whole cytoplasm appears foamy (the Virchow or Lepra (ell). The dermis in later stages of leprosy has large areas forming a continuous sheet of chronic inflammatory tissue with huge numbers of bacilli, and with lepra, mononuclear, and plasma cells.

In the dermis the early change in tuherculoid leprosy is the invasion by foci of mononuclear cells and histiocytes, usually located along the channels occupied by the neurovascular bundles. The histiocytes transform into epithelioid cells and occasional giant cells round a core of fine nerve twigs. By electronmicroscopy of ultra-thin sections the cytoplasm of epithelioid cells is seen to contain a smooth reticulum and diffuse lipoid dust, and mitochondria increase greatly during the active and reactive phases of tuberculoid leprosy. The epithelioid cells rapidly engulf and destroy leprosy bacilli and other tissues such as collagen and nerve fibres which are in their area. The nerve fibre changes are characteristic; beginning with Wallerian degeneration they go on to necrosis. Throughout all stages there is a continuous attempt at regeneration of nerve fibres in adjacent unaffected areas of skin, consisting of a sprouting of fine neurofibrils.

In dimorphous leprosy the lesion shows mixed characters in the same or different lesions of the same subject, and is an intermediate response to the infection.

Khanolkar comments on the above findings. The leprosy infection is probably transmitted by skin contact, by repeated or even single contacts of the bare skin of a susceptible person with the skin of a lepromatous case, and even also dimorphous and reacting tuberculoid cases. It appears that the bacilli must reach the external surface of the body in sufficient numbers. Even after they survive in the host and grow in his tissues they may not produce the disease. It seems that they must multiply rapidly and have a certain degree of biological activity so that the responses and reactions of the host become recognisable as clinical leprosy. It is still not known how the leprosy bacilli introduce themselves into the axoplasm of nerve fibres in the skin. NisHIURA thinks that it starts with the regenerating axon, whose terminal expansion actively phagocytises free-floating bacilli in the tissue fluids of the skin. The problem of the persistence of leprosy bacilli in the body for long periods of time, even after a long course of therapy, is probably due to their lodgement in Schwann cells, and the rapid multiplying and freeing of the bacilli in tissues outside the nerves must be influenced by general body conditions, such as puberty, pregnancy, intercurrent diseases, and unsuitable treatments. 
We still do not understand the factor or factors which determine the change of a histiocyte into an epithelioid or a Virchow cell. For the last 2 years KHANOLKAR has cultivated an acid-fast mycobacterium identical with $M$. leprae from 4 different cases of leprosy and kept it growing in artificial media. BINFORD and CHATTERJEE have reported experiments in laboratory animals which begin to throw light on transmission. KHANOLKAR has found some promise in similar experiments on mice.

14. Drs. A. Paul Jayraj and D. Chowdhury gave their papers on Epithelial and Subepithelial Innervation in Lepromatous Leprosy. They applied the silver impregnation method to biopsy material from the skin of 20 advanced lepromatous cases, and found intact nerve fibres in the epidermal and subepidermal layer of lepromatous skin. It is not known whether these fibres are carrying impulses or not.

15. DR. R. G. Cochrane read a paper on Immunity in Leprosy. He pointed out the difficulty of this subject. The strength of the lymphocytic response may be a measure of immunity in leprosy, and it may be used to assess the action of the lepromin test and of BCG vaccination. One injection of BCG may not produce an effective immunity and perhaps it will need to be given repeatedly. Further it is by no means certain whether the immune response, as indicated by the appearance of tissue allergy, is determined by the type of the disease or whether the allergic response determines the type of disease.

The lepromin reaction is usually regarded as merely an indication of the stage of immunity in the tissues. Dr. Cochrane expounded the concept of a conflict between the bacillus and the tissues, on the outcome of which either lepromatous or tuberculoid leprosy emerges. Thus established, tuberculoid leprosy is that form of the disease in which the tissues finally gain the upper hand. His concept of dimorphous leprosy relates the clinical and histological signs of leprosy to the individual immunity state. He thinks that erythema nodosum leprosum is a bacterial allergy and is produced when the bacilli are undergoing great changes in morphology, and that progressive lepra reaction has no direct bearing on immunity but is simply a biochemical reaction to circulating antibodies, as is indicated by the mobilization of plasma cells and the marked reversal of the serum globulin/albumin ratio in the blood.

16. Drs. B. M. Bragança and K. Prabhakaran reported on their studies of Some Aspects of the Metabolism of M. Leprae. They wished to explore the enzyme metabolism of $M$. leprae obtained from lepromatous nodules, first separating the bacilli from the nodular tissue by a method which did not inactivate the enzymes. They used differential centrifugizing and used aqueous solvents known not to denature proteins and enzymes. The final fractions were 
found free of tissue debris. The separated organisms were subjected to metabolic studies of two kinds, one the nature of the enzyme pattern by which the bacilli metabolise various substances to obtain the required energy, the other the nature of the enzymes involved in the metabolism of amino-acids. It was found that human leprosy bacilli contain several of the oxidative enzymes, namely cytochrome oxidase, succinic oxidase, cytochrome reductase, lactic dehydrogenase linked to DPN, and pyruvic oxidising enzymes. In general these indicate that the bacilli can obtain energy for cellular activity by the aerobic oxidation of nutrients such as glucose, lactate, and pyruvate. Unless the bacilli were crushed the aerobic metabolism could not be significantly demonstrated in vitro. This indicates that the lipoidal capsule around the mycobacteria may affect the accessibility of the various substrates tested to the enzyme centres in the cell. As regards amino-acid metabolism the work is at an early stage but it was found that both glutamic acid and tyrosine are actively metabolised by the separated organisms.

17. DR. K. Yanagisawa of Japan reported on his Studies on the Potency Test of Dharmendra Antigen. The potency of lepromin has previously been assayed mainly by the enumeration of leprosy bacilli of the antigen. However by analogy with similar studies on tuberculin and BCG reactions it seemed worthwhile estimating the potency of Dharmendra antigen by the grade of reaction itself rather than by enumeration of the bacilli. He carried out experiments on 3 lines $(a)$ Leprosy bacilli obtained by trypsinizing human lepromas were applied to sensitize guinea pigs: $(b)$ potency of different samples of Dharmendra antigen was compared in guinea pigs sensitized with leprosy and tubercle bacilli: $(c)$ potency of different samples of Dharmendra antigen was compared as between leprosy patients and guinea pigs sensitized with tubercle bacilli. The results all tended to show that assay of potency of Dharmendra antigen can be performed with guinea pigs sensitized to tubercle bacilli.

18. Drs. B. B. Gokhale and B. B. Desal gave a paper on Cholinesterase Activity in Leprosy. The physiological function of this enzyme in the blood stream is not yet clearly understood. It is possible that it is a mere barrier to destroy any acetylcholine which leaks out into the blood stream; but it is located in high concentration in the neuronal surface and its main function is to hydrolyse acetylcholine which is directly associated with the nerve action potential. This hydrolysis of acetylcholine is necessary for the return of the nerve to normal, and any condition that reduces or inhibits it will delay the return of the nerve to normal. The organic phosphorus insecticides have been found to inhibit cholinesterase by about $80 \%$ in some cases and typical neurological symptoms resulted in such cases. Therefore it was thought worthwhile to study the enzymatic activity of serum samples in normal cases and leprosy cases, and a 
statistically significant lowering of the activity was observed in the leprosy patients. This now provides a basis for a planned study in comparable groups of leprosy in various stages.

19. Dr. Y. K. Subrahmanyam described the Draft Scheme for the Third Five-Year Plan on Leprosy. It is estimated that there are about 2 million cases of leprosy in India, which is a moderate estimate. Working on the basis of this estimate and on an incidence of 20 per thousand in endemic areas (the incidence varies from 10 to 60 per thousand) the population to be covered would be 100 millions. So far the Government of India has established 72 units and aims at a target of 100 units by the end of the 2nd Five-Year Plan now in progress. In the Third Plan period a further 150 new control units would be needed to achieve full coverage. Two Rehabilitation Centres are planned, one in the southern and one in the northern zone, for each of which more detailed planning is required, and for each of which a sum of Rs. 25 lakhs $(£ 187,500)$ is expected to be needed. Training centres are very important and these will be provided by the State Governments, with a probable subsidy from the Central Government. About 4,600 paramedical and 1,900 social workers will be needed to be trained in the Third Plan Period. An All-India Training Centre in Physiotherapy and Orthopaedic Surgery is being discussed, in consultation with Dr. Paul Brand of Vellore Christian Medical College. A grant of Rs. 25 lakhs $(£ 187,500)$ is required for this purpose. For the purpose of the All-India effort to detect and treat 2 million cases of leprosy, each State Government will need a good leprosy organization. The finance of the Third Plan is visualized at Rs. 1,700 lakhs $(£ 12,750,000)$.

20. DR. H. K. Lall gave a paper on the Control of Leprosy. He reviewed the history of leprosy control in the past 40 years and warned that future control will not be too easy in spite of the possession of the sulphones. These should be used in mass treatment campaigns, with intensive surveys to detect early cases, and with education and propaganda not getting ahead of treatment. In propaganda we would be wrong to say leprosy is not at all infectious but try to keep away from extremes and on the right lines as the truth is revealed. Nor should we denounce segregation, as it has some value, notably the idea of night segregation. It is very important to have the right type of personnel, both medical and auxiliary. For the time being it is best to have a separate leprosy cadre.

21. Shri M. B. Diwan also gave a paper on the Control of Leprosy. He said that India can control leprosy in a reasonable period provided that we adopt a sane, practical, and scientific attitude towards the problem and obtain personnel who are devoted, intelligent, and properly trained. Also the programme should be carried out on a broad front without a break, with open mind to 
adopt all possible improvements, and with periodic assessments of progress. The sulphone treatment has great advantages, but it is neither specific nor bacteriocidal, and it can fail so that relapses occur and it is still not certain that it is of value for prophylaxis. Control by treatment alone, with isolation abandoned, is an attitude not scientific. However inconvenient or expensive, we cannot dispense with isolation. In a sympathetic prepared atmosphere voluntary isolation is quite practicable. There is still ample scope for the creation of new leprosy institutions with their special contributions, and the leprosy control scheme should use all good measures. More emphasis on educative programmes is much needed. Even among medical men and the educated classes prejudice against leprosy exists, and it should be broken down. Non-medical auxiliaries do most of the work in the present control schemes, and their selection and training needs to be improved. Voluntary associations should be welcomed to join in the leprosy campaign.

22. Mr. W. Balley gave a paper on A Work of Reconstruction. He defined rehabilitation and to the medical, social, and economic aspects he added the spiritual, for our ministry is to the whole man. So far there is a gulf between occupational and rehabilitation therapy, and these two should be brought together. There are four main groups of ex-patients, those who are incapable of work, those who can be taught to work in spite of their deformities, those who need training for a new job, and those who need help in finding a suitable job. He calculates that there may be about half a million leprosy ex-patients in India who cannot do economic work; some 855,000 capable of open competitive work, and some 165,000 capable of doing profitable sheltered jobs. Rehabilitation should begin to be thought of and planned right from the beginning of the patient's treatment, and the aim should be a co-operative effort between surgeon, social worker, business and industry. The leprosy patient should never need to become a beggar. He can become a useful citizen again.

23. DR. I. SANTRA gave a paper on Social Aspects Including Rehabilitation. He said that social service should be based on religion, and the impulse to leprosy work in India came from religious people and was approved by a saint (Mahatma Gandhi). In India there are at least 1,500,000 leprosy cases, out of which 300,000 may be infectious, and many are blind or deformed. The people should be educated to recognise the disease and to know about its curability and degree of infectivity. Cured cases must be received back into the community and we have to prepare both the patient and the community for that. Children of infective patients should be separated and given proper training to fit them for their own life. The provision of better food for the masses is very important. In India there is a greater incidence of leprosy where the food level is low. 
Rehabilitation should be a part of the work of every leprosy scheme.

24. Dr. S. D. Gokhale dealt with Social Aspects of Institutional Treatment. There is need of careful study of the family structure and social relationship among the leprosy patients. Many of them beg, not perhaps of their own choice, but becaúse they have no home and no other means of subsistence. It is mostly disfigurement which drives a leprosy case out of the community. For those with major disfigurement the social worker has a heavy job, for they need shelter, occupation, and good food. A leprosy beggar however may not want to be rehabilitated, and this problem needs special attention, which the author thought calls for special institutions, in which they can be handled with sympathy and understanding, and psychiatric therapy will be called for, as well as good counsel. There should be careful selection of vocations and jobs. The children of leprosy patients should be cared for, those infected as well as those free of the disease.

25. Shri H. Shamrau gave a paper on Leprosy Control. In leprosy surveys it is best to start with treatment and propaganda and then deepen and widen the survey work. There should be an AllIndia Leprosy Board at Delhi with branches in each State. Each leprosy scheme centre should have a medical officer, pharmacist, laboratory technician, and 8 to 10 paramedical workers, social workers, peons, sweepers, and a van driver, and 2 clerks for the office. Each centre needs a well-equipped mobile medical van, bicycles, and staff quarters. The centre should be placed in or near the district headquarters. Many treatment centres should be opened to which no patient should be made to walk more than 3 miles. Domiciliary treatment should be used as necessary, and the work of the auxiliary staff should be supervised by the medical officer. Advice on segregation and prevention should be given, and education of the public. Work by the patients should be encouraged and guided and rehabilitation schemes set going.

26. Dr. M. Masin gave a paper on An Effective Approach to the Leprosy Problem. The old dread of leprosy is yielding to advancing knowledge of its mild infectivity and curability, and it could easily be treated in general hospitals and dispensaries. It might be possible to attach special wards to these, but doctors should be adequately trained in all medical schools. Local bodies should take an interest in the leprosy campaign and share in it, and more emphasis should be laid on rehabilitation. More centres are needed for this, whether in older leprosy homes or specially established.

27. Shri T. N. Jagadisan spoke on The Principles and Practice of Rehabilitation in Leprosy. He said there is a great rise in the interest in this, and gave a list of the existing literature, and described the many institutions in India which are now actively engaged in rehabilitation work. He warned against accepting agriculture in 
every case as the ideal work for the leprosy patient: in many cases it is too heavy or too traumatic. Rehabilitation should be suited to every patient, and physiotherapy, surgical corrections, psychotherapy, social integration, public propaganda and persuasion, and preventive medicine and individual care enter into the whole task. It is a huge task but we should not despair, but learn from the domestic mouse "which bites away a huge bulk bit by bit".

28. Dr. P. SEN read a paper on Social Factors Demand Adrquate Attention. Since May 1958, he had studied the social aspects of leprosy to provide a basis for a mass educational programme for Savda, East Khandesh. He soon found there was need for training in social aspects to be given to the field workers and medical officers of the national leprosy control programme. These social factors hinder prevention and treatment and even influence the causation of leprosy. The environmental social factors which influence causation are poverty, poor housing, starvation, squalor, ignorance of the rules of health, and community prejudices. Even emotional disturbances may react adversely on leprosy. The fear and hostility and apathy of the other members of society also react adversely. As for the victim of leprosy, he is denied the means of livelihood, denied family and social life, even denied hospital facilities for the treatment of other diseases. He is often denied facilities for rehabilitation when the disease is arrested. Even the law is against him, for by the Hindu Marriage Act of 1955 leprosy of 3 years' duration is a cause for divorce.

Patients naturally react to all this by being reluctant to accept the diagnosis of the disease, by concealment of the disease, by depression and drift towards suicide, by loss of mental and moral fibre, by irregularity in taking treatment, by forced reliance on begging or private charity. These things tend to make the disease worse and delay cure.

The patient's family also suffers, especially from loss of the wage-earner's income, and from the discrimination against the children in education and marriage.

All these things come back on society in economic and social loss, and the ravages of the social stigma are as much as the disease itself. As much study and effort to counteract these social factors will be needed as studies in therapy and surgical correction of the disease.

29. Miss T. Surty gave a paper on Education. She gave an account of organised educational work in leprosy carried out in Greater Bombay. The plan of work includes posters for hospitals, clinics, bus stands, schools and colleges, railway stations, dispensaries, and exhibitions. Written material for publication comprised material for newspapers and magazines, medical journals, and goodwill advertisements. Folders, leaflets, and booklets were prepared for patients and relatives, schools and colleges, and 
exhibitions. Lectures, seminars, and talks were arranged for doctors and students and welfare and other organisations. Films are made for schools and colleges, cinemas, mills and factories, and for showing in endemic areas. Radio talks are obtained, and models, charts, and posters made for stalls in exhibitions. Three types of film documentaries are aimed at; $(a)$ for students, a film showing a variety of early lesions and precautionary measures; $(b)$ for cinemas, a film with a story with a human appeal, without depicting the advanced type of leprosy: (c) for the masses in endemic urban areas, a film showing early lesions leading to advanced stages, and the results of treatment, and precautionary measures. It is difficult to get the full cooperation of the press, as editors are more interested in the spectacular than the educational. One should not overlook the aesthetic appeal of attractive colours in posters and leaflets.

30. Drs. P. Sen and I. O. Deshmukh gave a paper on $A n$ Epidemiological Survey of Social Behaviour Toliards Leprosy. From almost all centres in the national leprosy campaign comes the report that a large number of patients do not attend well for taking the sulphone therapy, and remain indifferent to treatment. Hence the Hind Kusht Nivaran Sangh undertook an investigation at Savda through a special medical social scientist, Dr. P. Sen. He prepared 2 questionnaires, one for the patients and one for the general population, and it was found that most of the patients and the public were totally ignorant of the elementary scientific concepts of leprosy, that they have an elaborate set of ideas and beliefs about leprosy inherited from the past which are utterly useless in active control of leprosy, that there is excessive ostracism in social behaviour towards leprosy patients. In the beginning of the work at Savda the subsidiary clinics of the Centre had to be carried on at the roadsides or in the fields as village leaders would not permit them near human habitations. People in general and the village leaders and social workers avoided any contact with the workers of the Centre for fear of having to assist in case detection. People got annoyed if the workers visited their homes even on a courtesy call, lest their neighbours suspect they had anyone suffering from leprosy. The attitude of the medical practitioners in the area was not helpful. Since the social study was begun, there has been much improvement in the general atmosphere, with much cooperation, and the clinics have been rescued from the roadside and fields and brought in to dispensaries and offices. It shows how essential are publicity and health education.

\section{B. The Kondhica Leprosarium, Poona District Leprosy Committee}

This leprosy hospital was founded in 1910 and handed over by the Government of Bombay to the Poona Leprosy Committee in 1956. Under the care of the President, Dr. N. J. Bandorawala, and the Vice-President, Maj. Gen. B. Basu, and a very keen medical staff 
it has made very notable progress, not only in buildings, industries, and general administration, but has taken a leading part in the wave of advanced plastic and reconstructive surgery which happily is spreading over India and in which India leads the leprosy world. Dr. Paul Brand of Vellore and Sir Harold Gillies of London might be described as the inspirers and guides and their able pupils have voluntarily worked at Kondhwa with highly satisfying results. These were Dr. N. H. Antia, Dr. P. K. Bharucha, Col. B. B. Choksi, Dr. G. N. Khatri. The Editor in December 1959 had the privilege of a visit to Kondhwa and attests the amazing lift in morale there as the result of the work of these surgeons. Kondhwa could easily become a training centre for plastic and reconstructive surgery. There is a resident physiotherapist, Mr. W. Jennings. On the medical side there is also an equally high standard, under Dr. B. B. Gokhale and Dr. S. V. Marathe. There are many honorary workers as well as the permanent staff. Medical research could also develop profitably in Kondhwa. There are about 300 inpatients. The total budget is around $£ 7,500$.

The dynamic happy state of the work at Kondhwa was a revelation to the visitor. It seems it is due to; $(a)$ the wisdom of Government in handing over the work to a civic committee led by Dr. Bandorawala and Maj. Gen. Basu, every member of which committee is enlightened about leprosy and experienced in some section of community service; $(b)$ the introduction of physiotherapy, plastic, and reconstructive surgery which revealed to the patient that surgical relief would be added to medical relief, and that the patient was an individual whom his fellow-citizens thought worth the rehabilitation; $(c)$ the extraordinary outpouring of voluntary service by the citizens and by the specialist physicians and surgeons.

\section{Correction}

The postal address of the East African Leprosy Research Centre was given incorrectly on p. 68 of the "Leprosy Review", January, 1960. It should be P.O. Box 1044, Busia, Uganda. 